\title{
Academic Research Budgets
}

A Look Ahead with Special Emphasis on Research Enablement and Support

Jane Radecki

Roger C. Schonfeld 


\section{ITHAKA S+R}

Ithaka $\mathrm{S}+\mathrm{R}$ provides research and strategic guidance to help the academic and cultural communities serve the public good and navigate economic, demographic, and technological change. Ithaka $\mathrm{S}+\mathrm{R}$ is part of ITHAKA, a not-for-profit organization that works to advance and preserve knowledge and to improve teaching and learning through the use of digital technologies. Artstor, JSTOR, and Portico are also part of ITHAKA.

Copyright 2021 ITHAKA. This work is licensed under a Creative Commons Attribution 4.0 International License. To view a copy of the license, please see https://creativecommons.org/licenses/by/4.0/.

ITHAKA is interested in disseminating this brief as widely as possible. Please contact us with any questions about using the report: research@ithaka.org.

We thank Springer Nature for their sponsorship of this report. 
The United States university sector's research enterprise is an important national asset. It is highly competitive and highly innovative in ordinary times, and during the past year plagued by coronavirus it pivoted quickly to conduct urgently needed research on a new threat. Beyond its national and international significance, the research enterprise is also an enormous assetintellectually and financially-for each of the individual universities with a major stake in it.

At the high level, the pandemic may seem not to have done lasting damage. Indeed, in the current economic downturn, while universities have lost billions, ${ }^{1}$ externally funded research has proven to be the most resilient major revenue source for large universities. But we believe that this view, while accurate, may mask a set of concerns that deserves greater scrutiny and perhaps eventual mitigation.

In this paper, we examine some of the budgetary issues facing the scientific research enterprise. Ultimately, it is our belief that, whatever the resiliency of research revenues, there are nevertheless important risks. Most of these risks are concentrated in essential research support and enablement functions, because of how they are funded. The impact of these risks will vary in part by budget models and in part on university research emphasis. ${ }^{2}$

Our work here builds on several recently completed Ithaka $S+R$ projects. A landscape review about the impacts of COVID-19 on the research enterprise found substantial questions about the specific impacts on research budgets. ${ }^{3}$ An examination of the role and strategic priorities of the senior research officer at major research universities found that these university leaders emphasize the importance of research revenue, fundraising, and budget models in their work. ${ }^{4}$ A survey of academic library leaders examined budgetary and strategic decision-making in the fall of 2020.5 We are also grateful to Jason Owen-Smith, who also examined the impact of COVID-19 on research budgets, and possible paths forward, in 2020. ${ }^{6}$ This issue brief provides a summary of the disruptions of 2020 and their implications on the research support and enablement functions going forward. Our goal in this paper is to provide an overview of the key issues facing university budgets and research enablement and support services they fund, to

\footnotetext{
${ }^{1}$ Kery Murakami, "Public Research Universities Tell Congress They Lost \$17 Billion During Pandemic," Inside Higher Ed, January 28, 2021, https://www.insidehighered.com/quicktakes/2021/01/28/public-research-universities-tell-congress-they-lost-17-billionduring.

2 Jane Radecki, "University Budget Models and Indirect Costs: A Primer," Ithaka S+R, February 25, 2020, https://doi.org/10.18665/sr.314858.

${ }^{3}$ Jane Radecki and Roger C. Schonfeld, "The Impacts of COVID-19 on the Research Enterprise: A Landscape Review," Ithaka $S+R$, October 26, 2020, 1-34, https://doi.org/10.18665/sr.314247.

${ }^{4}$ Oya Rieger and Roger Schonfeld, "The Senior Research Officer: Experience, Role, Organizational Structure, Strategic Directions, and Challenges," Ithaka S+R, December 1, 2020, https://doi.org/10.18665/sr.314490.

${ }^{5}$ Jennifer Frederick and Christine Wolff-Eisenberg, "Academic Library Strategy and Budgeting During the COVID-19 Pandemic: Results from the Ithaka S+R US Library Survey 2020," Ithaka S+R, December 9, 2020, https://doi.org/10.18665/sr.314507.

${ }^{6}$ Jason Owen-Smith's research was funded by Springer Nature, who also funded the landscape review we conducted in fall 2020 , See "The U.S. Academic Research Enterprise (US-ARE): Possible Paths from the Pandemic", Springer Nature, October 21, 2020, https://resource-cms.springernature.com/springer-cms/rest/v1/content/18520894/data/v8.
} 
determine whether there are risks emerging for the research enterprise that deserve possible mitigation. ${ }^{7}$

\section{Research Funding}

It is impossible to examine the dynamics for research support and enablement outside the context of the larger research enterprise revenue and budget situation in the US. In this abbreviated overview, we sketch out some of the macro changes that are of greatest importance.

At the highest level, we expect federal research funding to continue for the foreseeable future. To be sure, it is unclear if federal research funding will grow. The funding added for urgent COVIDrelated work to the NIH especially, but also other federal research funding agencies, during the onset of the pandemic may only be temporary, ${ }^{8}$ but it illustrates the importance of the national academic research enterprise as a kind of reserve corps in a scientific emergency that can readily absorb additional resources and prioritize new work. On the other hand, the federal budget has exploded over the past year with various relief bills, and whether increased spending will be maintained, or a new era of austerity will emerge, is beyond our powers of prediction.

Other than the emergency additions to study and combat COVID-19, the federal government's base research funding had been flat for some years. ${ }^{9}$ While federal funding represents the largest share of research revenues for the university community, ${ }^{10}$ its share of research funding has been decreasing. This has substantial implications for research support and enablement.

The federal government negotiates an indirect cost rate, by university, every few years which it pays to universities in all federally awarded research grants. These indirect costs are intended to cover among other things research enablement and support. Today each university periodically renegotiates its own overhead rate with the government, but many have argued that these rates are insufficient to cover their costs. ${ }^{11}$ The Trump administration's early threat to vastly reduce

\footnotetext{
${ }^{7}$ As we were assessing research budget issues, we had in-depth open-ended conversations with several current and former university leaders, including provosts, chief research officers, and CFOs, at some of the largest research universities in the country. We thank Bob Ambach, Matthew Lester, Myron Gutman, Peter Schiffer, Richard Spies, James O'Donnell, Paul Courant, Adrian Hill, and Nick Wigginton for speaking with us and sharing so generously. We thank Kimberly Lutz for comments on an earlier draft of this paper.

${ }^{8}$ Representative Joe Courtney, “H.R.748 - CARES Act,” Pub. L. No. H.R.748, Public Law No: 116-136, 2020, https://www.congress.gov/bill/116th-congress/house-bill/748; National Institutes of Health (NIH), "Support for COVID-19 Research," COVID-19 Research, December 15, 2020, https://commonfund.nih.gov/covid19; National Science Foundation (NSF), "COVID-19 Response Funding Update," Facts, National Science Foundation (NSF), May 2020, https://www.nsf.gov/about/congress/funding\%20updates/5.8\%20to\%205.14\%20CARES\%20Act\%20Update.pdf.

${ }^{9}$ See Figure I. National Institute of Health (NIH) Funding, FY1995-FY2021 in the following report: Kavya Seakar, "National Institutes of Health (NIH) Funding: FY1995-FY2021", Congressional Research Service (CRS), May 12, 2020, https://fas.org/sgp/crs/misc/R43341.pdf.

10 "The federal government is the largest funder of academic R\&D, providing more than half (53\%, or around $\$ 42$ billion) of total funds in 2018." See figure 5b-5 on page 12 of the following report: Josh Trapani, Michael T. Gibbons, and NCSES, "Academic Research and Development," NSB-2020-2, National Science Board (NSB), Science \& Engineering Indicators, NSF, January 15, 2020, https://ncses.nsf.gov/pubs/nsb20202/academic-r-d-in-the-united-states.

11 Jocelyn Kaiser, "NIH Plan to Reduce Overhead Payments Draws Fire," Science, June 2, 2017, https://doi.org/10.1126/science.aan6926.
} 
indirect costs on federally funded research, while quickly eliminated, suggested that there could be some precarity in the indirect cost model. ${ }^{12}$

Beyond the federal government, other funders pay a lower indirect cost rate or may decline to pay for indirect costs altogether. A small piece of evidence of this pattern was the much trumpeted 2019 decision that several major private foundations would begin to pay the full costs of overhead on their grants. ${ }^{13}$ While their effort is to be celebrated, it only serves to illustrate the broader pattern that foundation grants seldom pay the fully loaded costs of the work they support.

Indirect costs are a hugely complex topic that merit an examination of their own, ${ }^{14}$ but in brief external research funding does not pay the entire costs of the research enterprise. Rather, other university revenue sources effectively subsidize the research mission. As the Council on Governmental Relations notes, "The university subsidy is a legitimate issue and one that must be addressed honestly and constructively by all stakeholders. The 26 percent administrative cap and sponsor policies and practices that limit F\&A reimbursement force universities to fund real, unreimbursed costs through non-federal revenue sources and, therefore, to potentially reduce investments in core missions and infrastructure. Ultimately, this impairs a university's ability to strategically plan and invest in its future research enterprise."15 Moreover, as the share of funding from non-federal sources has increased, the effective indirect cost rate on the overall research enterprise has declined. This placed university research on shakier ground well before COVID-19 hit other revenue sources such as net tuition, ${ }^{16}$ state appropriations, clinical service, and healthcare.

\footnotetext{
${ }^{12}$ Andrew Kreighbaum, "Threat to University Research," Inside Higher Ed, April 3, 2017, https://www.insidehighered.com/news/2017/04/03/hhs-secretary-proposes-cutting-reimbursements-fund-university-based-research; Science News Staff, "What's in Trump's 2018 Budget Request for Science?," Science, May 23, 2017, https://doi.org/10.1126/science.aal1224.

${ }^{13}$ Maria Di Mento, "Five CEOs of Wealthy Foundations Pledge to Do More to Help Charities Pay Overhead," The Chronicle of Philanthropy, September 4, 2019, https://www.philanthropy.com/article/five-ceos-of-wealthy-foundations-pledge-to-do-more-to-helpcharities-pay-overhead/?cid=gen sign in

${ }^{14}$ See Jane Radecki, "University Budget Models and Indirect Costs: A Primer," Ithaka S+R, February 25, 2020, https://doi.org/10.18665/sr.314858.

${ }^{15}$ COGR Costing Committee, "Finances of Research Universities," Council on Governmental Relations (COGR), June 19, 2014, https://www.aau.edu/sites/default/files/AAU\%20Files/Key\%20lssues/Research\%20Administration\%20\%26\%20Regulation/Financesof-Research-Universities-An-Updated-Snapshot-from-COGR.pdf

${ }^{16}$ For example, Moody's has forecast "median net tuition revenue is likely to decline $3.3 \%$ and $0.9 \%$ in fiscal 2021 for private and public universities, respectively, based on our annual tuition survey results. Patrick McCabe et al., "Higher Education - US: Lower Enrollment Due to Coronavirus Impact Will Lead To Weaker Tuition Revenue," Moody's Investors Service, October 28, 2020, https://www.moodys.com/researchdocumentcontentpage.aspx?docid=PBM 1250618.
} 


\section{Research Interrupted}

The grants awarded to universities to fund scholarly research are typically recognized as revenue only as corresponding expenses are incurred. For instance, in a multi-year grant, a funder might award $\$ 1$ million in year one, but the grant budget might require the funds to be spent over the course of three years. Even when the full cash award ends up in the university's bank account immediately, accrual accounting mandates that the university cannot recognize this as revenue. The expenses must be incurred in order for the revenue to be recognized. This ordinary principle of university financial operations had profound implications when vast swathes of the research enterprise were interrupted if not entirely shut down during the spring and summer of 2020.

In March 2020, universities in the US paused all but essential research in order to enable social distancing and other pandemic health-related priorities. Many did not restart laboratory research until the summer and some have kept field research on pause even longer. ${ }^{17}$

With research disrupted, the default expectation was that universities would not make grantfunded expenditures and would therefore be unable to recognize the associated revenue. While grant funds would remain in the university's bank account, the university would not be able to access the revenue despite incurring other costs, such as salary and benefits for researchers. Without direct expenditures to code to the grant, revenue could not be recognized.

Fortunately, many funding agencies recognized this dynamic and issued policy exceptions, allowing universities to continue recognizing anticipated expenses against existing grants even if the associated research projects could not be advanced as planned. ${ }^{18}$ This was an enormous financial relief in the first months of the pandemic.

More recently, many funding agencies have rescinded these policy exceptions. ${ }^{19}$ As a result, universities made restarting their research enterprise a major priority, coming up with creative solutions to ensure that the pace of scientific research can continue. Social distancing in laboratories, for example, has required that, in some cases, researchers work in multiple shifts or that they only stay in the lab when they are using its resources for experiments. Through these new guidelines a number of activities, such as conducting paperwork, literature searches, and manuscript writing and editing, are now taking place outside the confines of the lab and often at home. Universities have worked to ensure that the right arrangements are in place to allow the pace of the research enterprise to continue without undue interruption.

One side effect that seems less well understood is how performance outcomes will be measured for grants that have not yielded substantive research progress during this time. Some individuals shifted their focus for several months to writing and publishing, but missing months

\footnotetext{
17 Jane Radecki and Roger C. Schonfeld, "The Impacts of COVID-19 on the Research Enterprise: A Landscape Review," Ithaka $S+R$, October 26, 2020, https://doi.org/10.18665/sr.314247.

$18 \mathrm{lbid}$.

${ }^{19}$ Michael Rigas, "OMB M-20-26," Memorandum (Washington, D.C.: Executive Office of the President Office of Management and Budget, June 18, 2020), https://www.whitehouse.gov/wp-content/uploads/2020/06/M-20-26.pdf.
} 
of primary research will necessarily have an impact on outcomes. How if at all will performance and deliverable expectations be adjusted and taken into account when success is measured for renewals and new grant submissions?

Universities are concerned about the broader implications of this dilemma and have sought federal relief to address the concern. In a series of letters, a group of advocacy organizations for the research university sector urged Congress to provide financial relief to support the research enterprise, declaring that, "Without supplemental funding, federal research agencies will be forced to make difficult decisions between funding the completion of existing research projects or funding new projects-both are important to our nation's scientific competitiveness and economic recovery." 20 It remains unclear if such additional support will be provided and how relief funding and research funding will change under the Biden administration. If there is more relief funding, this will result in yet another temporary expansion of federally funded research.

\section{University Capacity}

Short-term boosts in research funding at a sector-wide level, as well as the uncertainty raised earlier about the long-term trajectory of federal research funding, raise questions about universities' capacity to absorb additional research work.

Owen-Smith recently noted that COVID-related funding distributed by the NIH on an urgent basis did not at all follow the typical patterns of overall NIH funding. ${ }^{21}$ This analysis suggests that a fairly wide array of research universities showed that they had the research capacity to absorb and utilize a sudden funding increase. More analysis would be needed in order to determine the degree of capacity broadly across the country.

However, there are natural limitations on this capacity in the short term. After all, in order to absorb a substantial increase in research funding, universities would need to provision greater laboratories and hire and enroll additional faculty members, post-docs, and grad students, to say nothing of the research support and enablement services we discuss below.

In the long run, it is possible to build additional laboratories and other research facilities, typically by issuing debt, ${ }^{22}$ which may be complicated right now in light of enrollment and net

\footnotetext{
${ }^{20}$ Mary Sue Coleman et al., "AAU, APLU, AAMC, and ACE Urge Senate to Provide At Least \$26 Billion for Research in Next COVID-19 Relief Measure," May 27, 2020, https://www.aau.edu/sites/default/files/AAU-Files/Key-Issues/COVID19/1ResearchReliefSenateLetter5-27-20Final.pdf; Peter McPherson et al., "AAU, Associations Send Letter to Congressional Leadership Urging Support for the US Research Enterprise," August 3, 2020, https://www.aau.edu/sites/default/files/AAU-Files/KeyIssues/COVID-19/1ResearchReliefSenateLetter5-27-20Final.pdf.

${ }^{21}$ Jason Owen-Smith, "The U.S. Academic Research Enterprise (US-ARE): Possible Paths from the Pandemic," Springer Nature, October 21, 2020, 42-44, https://resource-cms.springernature.com/springer-cms/rest/v1/content/18520894/data/v8.

22 "For decades, colleges and universities largely sold bonds to finance new construction of academic buildings, dorms and sports complexes, and to tackle deferred maintenance. Like many other municipal bonds, these offerings are typically tax-exempt. Some schools issue taxable bonds because they come with fewer restrictions governing use of the funds.... Hoping to address possible shortfalls and take advantage of ultralow rates, universities have flooded the market with debt." Rising yields on higher education bonds can be attributed to the fact that institutions' abilities to carefully navigate the COVID-19 pandemic came into question. Bond issuance came from countless institutions attempting to reduce their fixed costs. For some institutions, they found borrowing money at low rates to be significantly more attractive than risk having to dip into their endowments which could have a possible negative
} 
tuition pressures. ${ }^{23}$ Similarly, it is possible to hire additional researchers, although many universities are in fact cutting back on the start-up packages that they offer to newly hired researchers to get their research agenda off the ground.

The flip side is that some universities might choose to reduce the size of their research enterprise. Given that, as we noted, many universities believe that their research enterprise is cross-subsidized by other revenue streams, selective cutbacks to reduce the degree of crosssubsidization required could make sense. Of course, if adapted by a sizable number of large research universities, such an approach also would affect the competitiveness of the US research enterprise as a whole.

One mechanism by which this cross-subsidization occurs would be to reduce, if not eliminate, university contributions to "cost-share.”24 Many universities maintain a budget for cost-share, or that portion of a research project's direct costs that are not funded externally but rather covered by the university itself. Many large universities strongly discourage cost sharing, unless the commitment is required by the funder. ${ }^{25}$ Still, they typically budget for these funds, sometimes at least in part centrally through the senior research officer and in other cases on a more decentralized basis. As a result of budget cuts, institutions may reduce if not eliminate their budget for cost-share, thereby needing to forgo certain funders and partnerships that they might otherwise have pursued. Over time, this approach could result in a shift in research revenue sourcing if not a selective reduction in research capacity.

\section{Research Support and Enablement}

Funding for research support and enablement is perhaps the area of the research enterprise most at risk. These are the absolutely vital functions that make it possible for the university to seek and administer grants, for the university to comply with various regulations, and for the university to support research. While they are sometimes organized or understood as administration and overhead, and while some universities seek to streamline certain elements of this work, little research could take place without them. ${ }^{26}$

cost to future generations of students. See Juliet Chung and Melissa Korn, "Bond Boom Comes to America's Colleges and Universities," The Wall Street Journal, December 26, 2020, https://www.wsj.com/articles/bond-boom-comes-to-americas-collegesand-universities-11608978781.

${ }^{23}$ Patrick McCabe et al., "Higher Education - US: Lower Enrollment Due to Coronavirus Impact Will Lead To Weaker Tuition Revenue," Moody's Investors Service, October 28, 2020, https://www.moodys.com/researchdocumentcontentpage.aspx?docid=PBM 1250618.

${ }^{24}$ There are primarily three types of cost sharing that can occur on sponsored projects: (1) mandatory cost sharing, (2) voluntary committed cost sharing, and (3) voluntary uncommitted cost sharing. NC State University, "Cost Sharing," Research Administration and Compliance, 2021, https://research.ncsu.edu/administration/compliance/fiscal-compliance/cost-sharing/.

${ }^{25}$ For example, see Harvard's cost sharing policy: Harvard University, "Cost Sharing Policy," Office for Sponsored Programs, April 2020, https://osp.finance.harvard.edu/cost-sharing-policy.

${ }^{26}$ Many of these issues around support and enablement, including the budget models, were explored in Oya Rieger and Roger Schonfeld, "The Senior Research Officer: Experience, Role, Organizational Structure, Strategic Directions, and Challenges," Ithaka $S+R$, December 1, 2020, https://doi.org/10.18665/sr.314490. 
Budgetarily, there are two principal categories of research support and enablement: cost recovery services and overhead services. In the following sub-sections, we examine overhead, some exceptions to the overhead model, and cost recovery services. Budgetary pressures can vary significantly as a result.

\section{Overhead-and Pressures on the General Fund}

The more common category of research support and enablement is budgeted out of general funds as overhead against core research activities. This category includes many services that often report up to the senior research officer, such as compliance, proposal development, and research administration. The research library and many research data services are also budgeted as overhead.

Because budgets for these services are derived from university general funds, whenever there is pressure on the general fund, financing for these services is at risk. The general fund is derived from tuition, state appropriations, clinical and healthcare services, indirect costs from sponsored research, and various ancillary services-all of which have been under pressure or in decline as a result of the pandemic. ${ }^{27}$ In a responsibility center management institution, these issues are addressed in a more distributed fashion but the overall impacts are expected to be quite similar. ${ }^{28}$

The effects on these important research enablement and support services is only beginning to become clear. In the case of the research library, there is already substantial quantitative evidence of budget cuts. ${ }^{29}$ In addition, many libraries did not receive a timely budget for the 2020-2021 academic year, and in many cases they are under various forms of expenditure control. Libraries have already reduced spending on collections and made reductions to staffing. There is every reason to anticipate that these cuts will not only continue, but deepen next year. ${ }^{30}$

Other research support and enablement services will follow a similar trajectory. In interviews with senior research officers, several reported the "full expectation of needing to make extensive cuts to the research office even though revenues from research activities are steady or growing." ${ }^{31}$ As a result, they will need to reduce their services, perhaps by increasing turnaround time for grant submissions, to take one possible example.

\footnotetext{
${ }^{27}$ Jane Radecki and Roger C. Schonfeld, "The Impacts of COVID-19 on the Research Enterprise: A Landscape Review," Ithaka $S+R$, October 26, 2020, https://doi.org/10.18665/sr.314247.

28 Jane Radecki, "University Budget Models and Indirect Costs: A Primer," Ithaka S+R, February 25, 2020, https://doi.org/10.18665/sr.314858.

${ }^{29}$ Lindsay McKenzie, "Libraries Brace for Budget Cuts," Inside Higher Ed, April 17, 2020, https://www.insidehighered.com/news/2020/04/17/college-librarians-prepare-looming-budget-cuts-and-journal-subscriptions-couldbe.

30 Jennifer Frederick and Christine Wolff-Eisenberg, "Academic Library Strategy and Budgeting During the COVID-19 Pandemic: Results from the Ithaka S+R US Library Survey 2020," Ithaka S+R, December 9, 2020, https://doi.org/10.18665/sr.314507.

${ }^{31}$ Oya Rieger and Roger Schonfeld, "The Senior Research Officer: Experience, Role, Organizational Structure, Strategic Directions, and Challenges," Ithaka S+R, December 1, 2020, https://doi.org/10.18665/sr.314490.
} 


\section{Two Exceptions}

There are at least two exceptions to the broad pattern of these services being budgeted as overhead. First, especially in the case of the library, while the general fund is almost always the main source of funding, in some institutions it also receives a share of restricted funds from the endowment. This source may be at risk during periods of endowment and market volatility, which was an especially great concern in the spring of 2020 as US public markets dropped steeply in value at the onset of the pandemic. Many endowments ended FY 2020 down, even if they may have recovered since, while endowment spending increased for many institutions. ${ }^{2}$ Endowment spending is also often inflexible due to donor restrictions. 33 Still, endowments for research support and enablement are useful in that they can follow a different course than the general funds. It will be interesting to see if more universities attempt to raise endowed funds to support other research enablement and support services beyond the library.

Second, a small number of universities budget for a substantial portion of research support and enablement services on what is essentially a restricted basis. Their model allocates a fixed share of the indirect costs derived from grants to fund these services. This model allows the budget for such services to grow commensurately if the grant-funded research enterprise grows and to shrink naturally if it shrinks. The budgetary independence of this model provides substantial protection for a set of research support and enablement services during a downturn. We are not aware of a case where any portion of the library's budget is covered by such a restricted fund model. 34

\section{Cost Recovery Services}

Research cores, as they are known colloquially, are the instruments and services shared by multiple researchers and sometimes on an institution-wide or even cross-institutional basis that range from microscopes to telescopes and include animal care, nuclear facilities, and more. While the capital costs of acquiring or constructing these facilities is typically borne by the university, the operating costs for research cores, which largely consist of expert personnel, are often funded on a cost recovery basis. When a researcher plans to use a core, the grant to support the project is used to pay the relevant fees. Research cores are therefore to a large degree exempt from the concerns noted above about reductions in general funds. Unfortunately, during the pandemic, research cores have experienced a different budgetary challenge.

While research projects were substantially disrupted in spring 2020, there was little prospect of utilizing many research cores. Subsequently, with research restarted, but taking place under a

\footnotetext{
${ }^{32}$ Audrey Williams June, "College Endowment Spending Rose and Returns Fell as the Pandemic Set In," The Chronicle of Higher Education, February 19, 2021, https://www.chronicle.com/article/college-endowment-spending-rose-and-returns-fell-as-thepandemic-set-in.

${ }^{33}$ Sandy Baum, Catherine Bond Hill, and Emily Schwartz, "College and University Endowments: In the Public Interest?," Ithaka $S+R$, May 22, 2018, 1-45, https://doi.org/10.18665/sr.307377.

${ }^{34}$ See Oya Rieger and Roger Schonfeld, "The Senior Research Officer: Experience, Role, Organizational Structure, Strategic Directions, and Challenges," Ithaka S+R, December 1, 2020, 11-12, https://doi.org/10.18665/sr.314490.
} 
variety of restrictions, some research cores are probably less productive. As a result, usage fees for research cores in 2020 were substantially lower than had been anticipated.

This effect on revenue for research cores was substantial enough that a group of advocacy organizations for the university community requested that Congress provide "emergency relief to sustain research support personnel and base operating costs for core research facilities and user-funded research services until such time facilities reopen and research activities return to pre-pandemic activity levels....Relief funds for this purpose would be primarily used to sustain research personnel employment.” 35

It is noteworthy that universities focused their request for relief for research support and enablement services on research cores rather than also making the argument that relief was needed for the various services provided out of general funds, such as the library, which are themselves receiving cuts.

\section{Conclusion}

Amidst the ongoing pandemic and economic downturn, externally funded research has been the most reliable and resilient major source of revenue for large US universities. But, there are real risks to a variety of research enablement and support services. Universities could benefit from assessing these risks against their research strategy, including their budgetary reliance on research revenues. Some universities may find value in a more comprehensive approach to these risks and their mitigation.

Looking ahead, there is no guarantee for the future, and for now much turns on the plans of the new Biden administration. How will the new administration's stated support for science lead to funding for general basic and applied research? And, will the Biden administration enact further policy exemptions for previously awarded funding or provide further funding for researchers whose work was interrupted in the spring of 2020? Will there be targeted relief for research support and enablement services? Any decrease in available funding levels could impose further strain on university budgets and greater competition among researchers to secure necessary funding, while also reducing the contributions of the national research enterprise as a whole.

\footnotetext{
${ }^{35}$ Mary Sue Coleman et al., "AAU, AAMC, APLU, ACE COVID-19 Research Recommendations," April 7, 2020, https://www.aau.edu/sites/default/files/AAU-Files/AAU-AAMC-APLU-ACE\%20COVID19\%20Research\%20Recommendations\%2047-20.pdf.
} 